Review Article

\title{
Biomechanics in Removable Partial Dentures: A Literature Review of FEA-Based Studies
}

\author{
Mohammed A. Mousa $\mathbb{D}^{1,2}$ Johari Yap Abdullah $\mathbb{D},{ }^{3}$ Nafij B. Jamayet $\mathbb{D}^{4}$, \\ Mohamed I. El-Anwar ${ }^{(D)}{ }^{5}$ Kiran Kumar Ganji, ${ }^{6}$ Mohammad Khursheed Alam $\left(\mathbb{D},{ }^{6}\right.$ \\ and Adam Husein $\mathbb{D}^{1}$ \\ ${ }^{1}$ Prosthodontic Unit, School of Dental Sciences, Universiti Sains Malaysia, 16150 Kubang Kerian, Kelantan, Malaysia \\ ${ }^{2}$ Department of Prosthetic Dental Sciences, College of Dentistry, Jouf University, Sakakah, Jouf, Saudi Arabia \\ ${ }^{3}$ Craniofacial Imaging and Additive Manufacturing Laboratory, School of Dental Sciences, Universiti Sains Malaysia, \\ 16150 Kubang Kerian, Kelantan, Malaysia \\ ${ }^{4}$ Division of Restorative Dentistry, School of Dentistry, International Medical University, Bukit Jalil, Jalan Jalil Perkasa 19, \\ 57000 Kuala Lumpur, Malaysia \\ ${ }^{5}$ Mechanical Engineering Department, National Research Centre, Giza, Egypt \\ ${ }^{6}$ Department of Preventive Dentistry, College of Dentistry, Jouf University, Sakakah, Saudi Arabia
}

Correspondence should be addressed to Mohammed A. Mousa; dr.mohammed.assayed@gmail.com, Mohammad Khursheed Alam; dralam@gmail.com, and Adam Husein; adamkck@usm.my

Received 1 July 2021; Revised 23 July 2021; Accepted 30 July 2021; Published 27 August 2021

Academic Editor: Vincenzo Iorio Siciliano

Copyright (c) 2021 Mohammed A. Mousa et al. This is an open access article distributed under the Creative Commons Attribution License, which permits unrestricted use, distribution, and reproduction in any medium, provided the original work is properly cited.

The present study was aimed at reviewing the studies that used finite element analysis (FEA) to estimate the biomechanical stress arising in removable partial dentures (RPDs) and how to optimize it. A literature survey was conducted for the English full-text articles, which used only FEA to estimate the stress developed in RPDs from Jan 2000 to May 2021. In RPDs, the retaining and supporting structures are subjected to dynamic loads during insertion and removal of the prosthesis as well as during function. The majority of stresses in free-end saddle (FES) RPDs are concentrated in the shoulder of the clasp, the horizontal curvature of the gingival approaching clasp, and the part of the major connector next to terminal abutments. Clasps fabricated from flexible materials were beneficial to eliminate the stress in the abutment, while rigid materials were preferred for major connectors to eliminate the displacement of the prosthesis. In implant-assisted RPD, the implant receive the majority of the load, thereby reducing the stress on the abutment and reducing the displacement of the prosthesis. The amount of stress in the implant decreases with zero or minimal angulation, using long and wide implants, and when the implants are placed in the first molar area.

\section{Introduction}

The main objective of removable partial dentures (RPDs) is to provide prosthetic rehabilitation of missing teeth and associated structures, with avoidance of further loss of remaining teeth. RPDs are indicated (in terms of aesthetic and masticatory efficiency) when the edentulous span is extensive, horizontally and vertically, to be treated with conventional fixed dental restoration because of the excessive resorption that may happen following extraction $[1,2]$. RPDs are still con- sidered a cost-effective treatment option in partially edentulous patients, compared to fixed and implant-retained restorations [3]. Although there was no worldwide metaanalysis report about the prevalence of patients wearing RPD, up to the authors' knowledge, there was an agreement that the number of partial edentulism is increasing in the United States and the United Kingdom [4-6], with more prevalence in female patients [7]. In Brazil, Kennedy class I was the most prevalent lower edentulism, while Kennedy class III was the most frequent maxillary one [7]. 13\% of 
the United Kingdom population was reported wearing RPDs, while $6 \%$ wear complete dentures $[8,9]$. As per the mentioned reports, RPDs still provide realistic and predictable treatment options, and therefore, all efforts should be done to design adequate prostheses that serve efficiently with no or minimal damage.

The prosthetic management of partially edentulous patients with RPDs remains to face challenges due to varieties of factors including dental factors, patient's factors, and factors related to the prosthesis itself [10-12]. Components of the prosthesis are subjected to stress and, at the same time, can produce stresses in the supporting structures as well [13]. Abutment teeth, as supporting and retaining structures to the prosthesis, are subjected to stress during function, insertion, and removal of the prosthesis. If this stress exceeded their natural resistance, this may result in resorption in the supporting alveolar bone, loss of the abutment, and, eventually, failure of the prosthesis $[14,15]$. In the same way, the freeend saddle prostheses are subjected to stress during function, resulting in bone resorption, loss of the support, and loss of stability of prostheses, which necessitate a frequent replacement $[16,17]$. Implant-assisted RPDs showed welcomed treatment modalities compared with the conventional RPDs, in terms of preserving supporting structures, optimizing the retention and stability of the prostheses, improvising the chewing efficiency, and improving the quality of patient life [18-21]. On the other hand, the implant does not show the same tolerance of the natural tooth to the different kinds of occlusal force which, if it exceeded its limit, may result in bone resorption around the implant or even fracture of the implant itself $[22,23]$. The occlusal considerations, design of the prosthesis, implant length, diameter, and macro- and microsurface texture of the implant, bone quantity, and patient factors, play a major role in the survival of implants [24-26].

The biomechanics of oral structures and prosthetic restoration used in dentistry highly influence the long-term success of dental treatment. Therefore, it was crucial to investigate the biomechanical interaction between supporting structures and the overlying prosthesis, in order to control it, to preserve the remaining structures and to maintain the prosthesis working adequately $[27,28]$.

Measurement of stress in abutment teeth, implants and surrounding structures, and prostheses has been performed using diversities of methods including analytical, numerical, and experimental methods [29]. Experimental methods such as electrical strain gauges can provide point-to-point precise quantitative measurement to the stress distribution in in vivo and in vitro scenarios [30], while photoelasticity can provide a full-field qualitative measurement of the same kind of stress [31]. Each technique of experimental methods has its advantages and limitations, which make it necessary to use two or more methods to identify the stress and strain in any area of interest $[31,32]$.

Finite element analysis (FEA), as a numerical method, has been approved as a proficient way of providing qualitative and quantitative mathematical data of the biomechanics of different dental prostheses and their supporting structures [33-37]. The main advantage of FEA is the capability to work with complex situations (or defects) and creating their corre- sponding prostheses virtually without the need to get ethical approval [38]. FEA can be performed by achieving the personal data from laser scanning, Cone Beam Computerized Tomography (CBCT), Magnetic Resonance Imaging (MRI) or even simulating the design using available computeraided engineering software. This is followed by customized segmentation, specifying the properties of the materials, getting the model, meshing it, loading that model, and, finally, getting the solution to the problem (Figure 1) [33, 35, 39]. Introduction of nonlinear contact analyses in FEA has solved the soft tissue behavior, problems of sliding, prediction of the deflection and permanent deformation of clasp arms, and the friction phenomena that happen between the prosthesis and abutment teeth and at the proximal contact surfaces between adjacent teeth $[40,41]$. Figure 2 shows the problems that FEA can solve in dentistry.

Although the study of biomechanical stress developed in RPDs using FEA is rapidly expanding, there was no broad review in the literature, up to the best of authors' knowledge, concerned with the collection of the stress developed in RPDs and how to minimize it. The purpose of the present review was to identify the distribution of the biomechanical stress in components of RPD and their supporting structures, to elaborate the causes of this stress, and to optimize prostheses design in order to reduce this stress, from the point of perspective of FEA studies. The disparate themes and data make this study unsuited to be in the form of an ordinary systematic review or meta-analysis study.

\section{Strategy of the Literature Search}

This study is a part of a $\mathrm{PhD}$ research protocol approved by the Human Research Ethics Committee of Universiti Sains Malaysia (HREC/USM) with JEPeM Code: USM/JE$\mathrm{PeM} / 21030222$. An electronic search was conducted by using "Google Scholar, Saudi Digital Library (SDL), PubMed, Scopus, and Web of Science (WOS)" database research tools. The keywords used for the present study were chosen to be more general ("finite element analysis", "implant-assisted RPD", and "removable partial denture") to allow extraction of all relevant data. The initial search was done in "Google Scholar" by the first 3 authors (M.A.M., J.A., N.J.), "SDL" by (M.A.M., K.K.G.), "PubMed and Scopus" by (M.K.A., M.E.), and "WOS" by (J.A., A.H.). The titles and abstracts of the data sources were screened over nearly one month. When an article was found relevant to the objective of our study, its references were screened for further studies that meet the inclusion criteria. The search was done to find answers for the question "what are the factors contributing to the development of the biomechanical stress in RPDs and how to minimize it?" Table 1 shows the inclusion and exclusion criteria of the present review. All picked articles were collected, the required data were extracted, and duplicated articles were excluded from the study. Although there are different software programs, techniques are currently available for performing FEA studies; however, FEA is a numerical process with reproducible data of the same quality. 

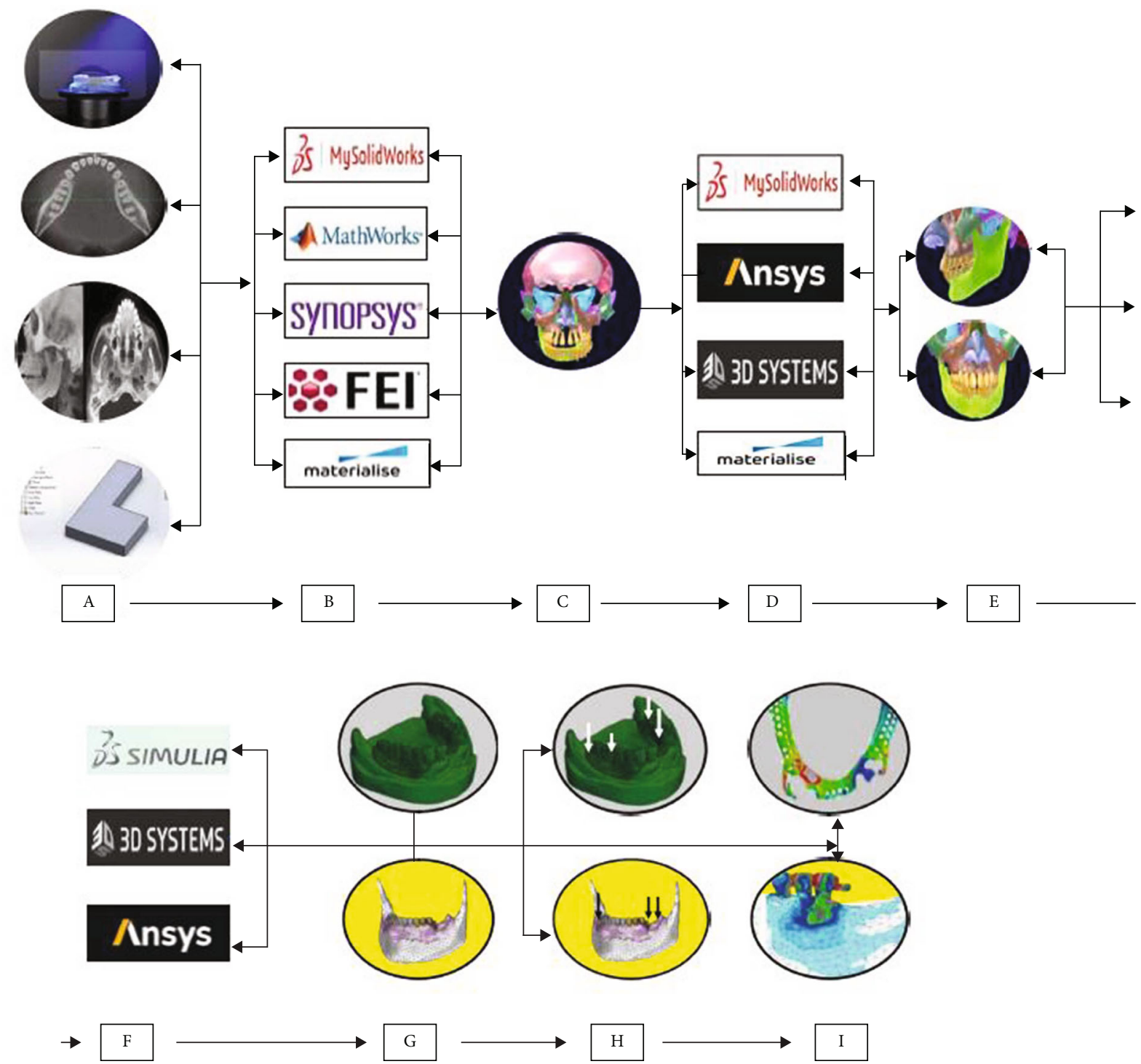

Figure 1: The workflow steps of finite element analysis.

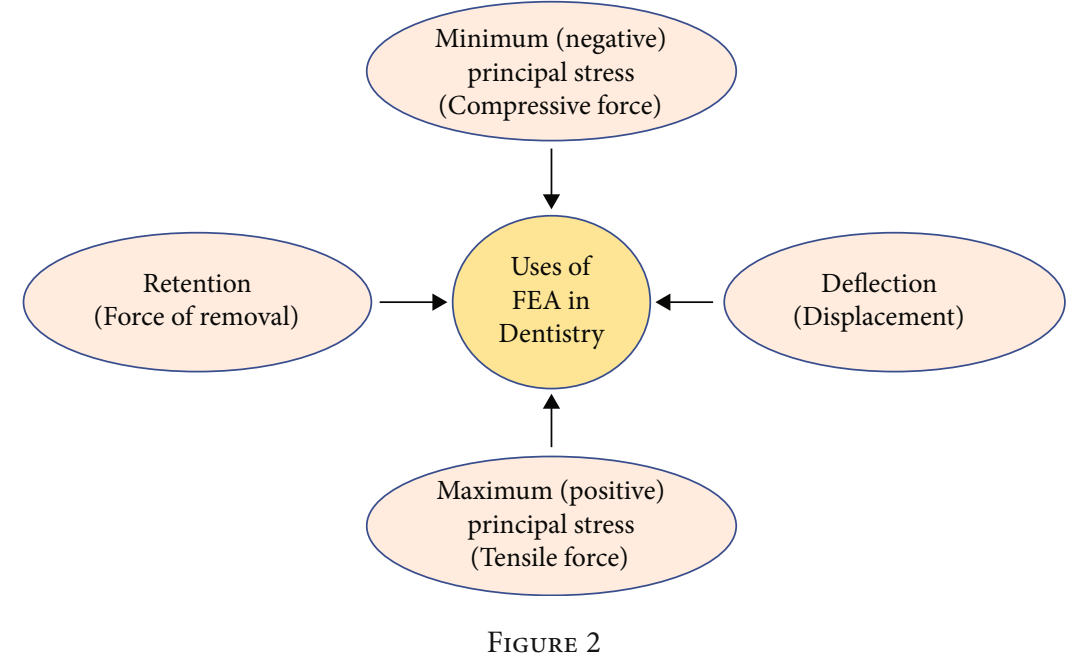


TABLE 1: Inclusion and exclusion criteria.

\begin{tabular}{ll}
\hline Inclusion criteria & Exclusion criteria \\
\hline 1. Only studies that used FEA & 1. Experimental and in vivo studies \\
2. Full-text studies & 2. Letter to editor or conference studies \\
3. From Jan 2000 to May 2021 & 3. Before Jan 2000 or after May 2021 \\
4. Only in English or translated papers & 4. Other than English or not translated studies \\
5. Only studies conducted on RPD & 5. The studies conducted in removable complete or fixed restoration \\
\hline
\end{tabular}

\section{Results and Discussion}

During the selected times, 8258 articles were surveyed. Out of these articles, 8178 were excluded based on screening of the title and abstract (as they do not relate to the objectives of the current review), while 44 articles were finally recruited for this study $[17,21,36,42-82]$. The initial causes of exclusion of articles were the articles worked on complete, maxillofacial, fixed, and non-FEA methods. Figure 3 shows the prevalence of conducted English studies that used FEA in RPDs in the last 20 years. It shows an increase in publications of FEA studies in 2020 compared to 2008 and before (except 2018, which showed zero publications). The results were extracted and grouped to identify the targeted problem and how to solve it. Among the selected articles, 14 studies have reported the influence of different retainer designs [44, 5567], while seven studies measured the influence of different designs and materials of major connectors [66, 69-74], and the studies concerned with implant-assisted RPD were ten articles [17, 43, 55, 76-82]. The results were broad-covering with heterogeneous and disparate data, which made it not compatible to be a meta-analysis or systematic review. For this, a form of narrative review has been chosen for the current research.

There is no disput about the fact that the long-term success of RPDs is directly proportional to the extent of control of various stresses induced by them on the supporting structure. This concept is emphasized by a long history of evaluation of each type of stress and suggesting the optimal design and materials for bringing them to the physiologic limits of the supporting structure [28]. According to the literature, the stress from the RPD components arises from either an accurately designed and fabricated prostheses or prostheses with inaccurate design or fault fabrication. The stress arising from an accurately designed prosthesis is affected by prosthesis (or prosthodontist) factors and patient's factors. The factors relating to the prosthesis include major connector designs, retainer designs, locations of the occlusal rest, properties of denture material, extension of edentulous saddles, and the presence or absence of implant/s. The factors related to the patient include age, ridge shape and form, occlusal force, and type of torque on the prosthesis. The stress arises from inaccurately designed prosthesis including thickness of the framework of the prosthesis, design of the major connector, thickness of the occlusal rest, and selection of the materials $[27,28]$. As all FEA studies assumed that the designed prostheses are optimal, regarding the design and materials, and well fitted on their model, the current review focused on the influence of different RPD designs and materials in the development of the stress and how to manage it. To be more convenient to readers, the findings have been categorized under the main titles "Identification areas of stress concentration and deflection in RPDs" and "Factors affecting the biomechanical stress in RPDs".

3.1. Areas of Stress Concentration in RPDs. Although there was a shortage in the literature regarding the identification of stress distribution in tooth-supported RPDs, FES scenarios got much interest regarding this interest. It was found that the terminal abutment shows a concentration of the stress in the apical and distal side [42], while the residual ridge shows the main stress concentration at the occlusal and lingual side when the saddle is short [36], and both of the mesial and distal area when the saddle is long [43]. The most common areas of FES RPD components subjected to stress during function of the prosthesis include; the minor and major connector lingual to the terminal abutment, the horizontal curvature of the gingival approaching clasp [44], and the shoulder of the Aker and back action clasp (Figure 4) [45, 46]. However, the proper design of the prosthesis makes the stress concentration be within the yield strength of the Co$\mathrm{Cr}$ alloy, which results in an extension of the survival rate of the clasp to 5.5 years $[45,46]$.

In implant-assisted RPDs, the stress is concentrated evenly around the implant if they were fully implantretained [21]. In the case the scenario was FES RPDs, the stress is mainly concentrated in the mesial side of the implant $[49,50]$, while the stress in abutments and residual ridges is significantly decreased regardless of the position, length, or width of the implant used $[47,48]$.

3.2. Displacement and Deflection in RPDs. The displacement induced by RPD mainly results from the deflection of the prosthesis, which was affected by mechanical properties of the base materials and the length of the saddle. As the rigidity of the major connector increases, the defection of the denture base materials decreases, while the stress in abutments and implant increases. The displacement of FES RPD is concentrated in the posterior part (distal) of the saddle of the prosthesis. As the saddle length increases, the displacement increases $[43,51]$. To minimize the adverse effect of long FES RPDs on supporting structures, implant-assisted RPD would be considered $[52,53]$. Upon using implant-assisted $\mathrm{RPD}$, the displacement of the prosthesis significantly decreases regardless of the length, position, width, or inclination of the implant $[50,54]$. 


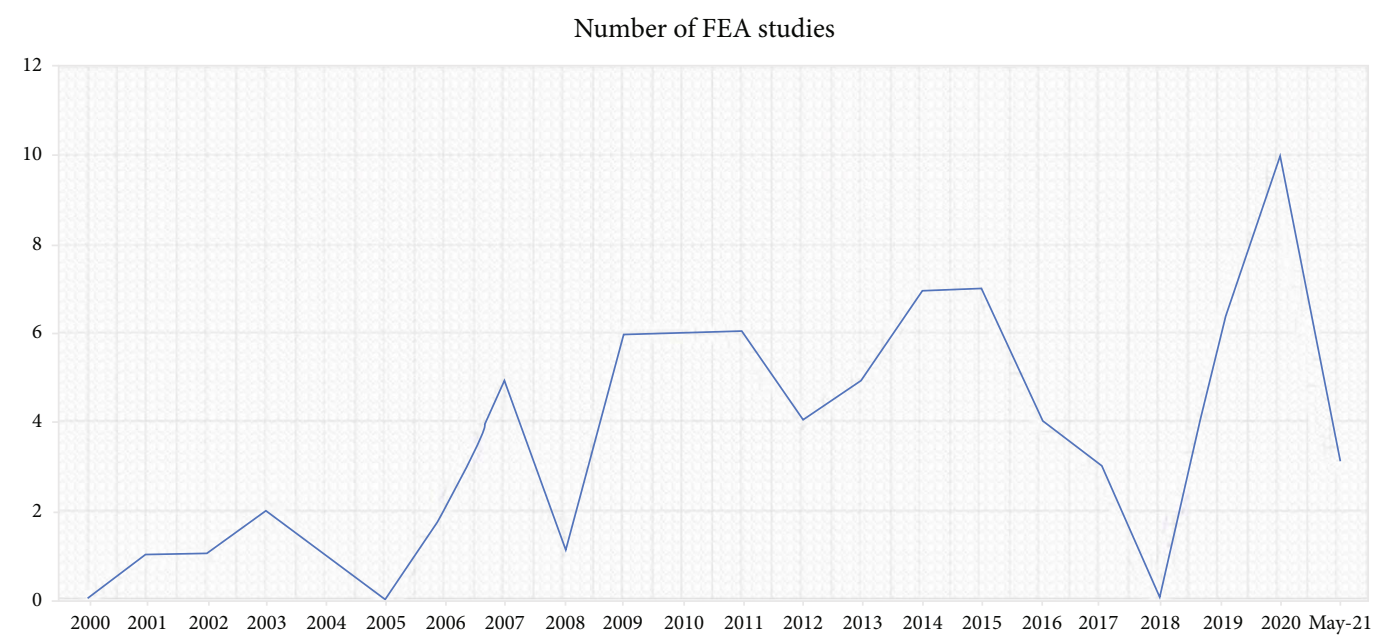

FIgURE 3: The graph shows the number of FEA studies conducted on RPDs from 2000 to May 2021.

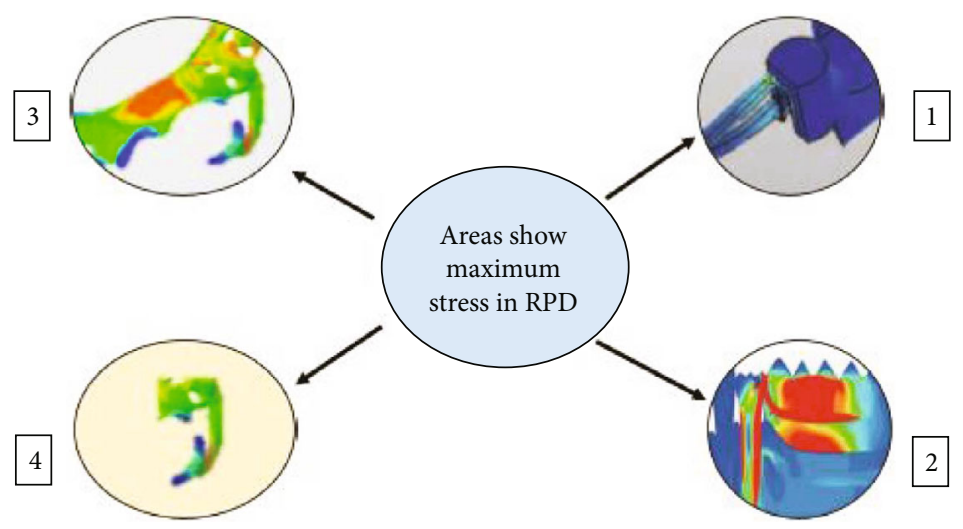

FIGURE 4: The portions of RPD components that receive the maximum stress.

3.3. Factors Affecting the Biomechanical Stress in Conventional RPDs. To overcome adverse effects of biomechanical stress in RPDs and decrease the stress on the supporting structures, a variety of different approaches have been advocated in the FEA literature.

3.3.1. Design of Retention. The retention of conventional RPDs is mainly gained from the adjacent teeth and underlying tissues. There are different types of retainer systems such as occlusal approaching clasps, gingival approaching clasps, rigid and nonrigid attachment systems, telescopic crowns, and implant/s. Table 2 shows that the studies evaluated the different retainer designs and their influences on the stress and displacement of RPDs.

For bounded saddles, although the circumferential Co-Cr clasp showed the maximum force of removal, maximum rigidity, and highest stability to the prostheses, it exhibits the maximum stress on the abutment teeth [55]. Moreover, the clasp arms are subjected to stress that concentrated at the junction of arms and the body of minor connector, which may result in loss of efficiency or even fracture of the clasp [46]. The magnitude of the stress depends on the depth of undercut, the length of the clasp, and the material of construction [55]. To decrease the stress arising in Co-Cr cir- cumferential clasps, a formula was introduced to optimize the length and width of the clasp. According to this formula, the clasp should be a half-round shape with $\mathrm{W} 2 / \mathrm{W} 1=0.6$ and $T / L=0.5$ to express the least stress, while $\mathrm{W} 1$ is the width of the clasp at the base, W2 is the width of the clasp at the tip, $T$ is the thickness, and $L$ is the length [56]. More flexible materials were introduced to substitute the Co-Cr materials as well. Among these materials, titanium alloys, gold alloys, polyetheretherketones (PEEK), polyamides, polyoxymethylenes, and acetal resin are examples [55, 57]. Clasps made from polyamides, followed by polyoxymethylenes, were found to produce the least amount of stress on abutment teeth compared to clasps made of Co-Cr and titaniums, regardless of the depth they engage [55]. In the same respect, the clasp made of acetal resin results in less stress when compared with the Co-Cr clasp, despite the retention not being comparable between $\mathrm{Co}-\mathrm{Cr}$ and acetal resins [57].

In FES RPDs, there are diversities of retainer designs that can be used. Gingival approaching clasps as a most used retainers for FES RPD received the most interest in the literature. When compared with Aker, reverse Aker, and embrasure clasp, the I-bar clasp (of the same material) shows a less distal displacement and stress in PL of abutment teeth when engaged in a 0.01 -inch undercut, while the embrasure clasp 
TABLE 2: Studies reporting the influence of different retainer designs on stress and displacement of conventional RPD.

\begin{tabular}{cclll}
\hline Authors & $\begin{array}{c}\text { Type of } \\
\text { prosthesis }\end{array}$ & $\begin{array}{l}\text { The examined independent } \\
\text { variable }\end{array}$ & $\begin{array}{l}\text { Materials used in } \\
\text { the denture }\end{array}$ & $\begin{array}{c}\text { Reported dependent } \\
\text { variable } \\
\text { Displacement } \\
\text { deflection }\end{array}$
\end{tabular} Outcome

Richert

et al. 202

[60]

FES RPD

Optimizing the length of I-bar clasp

18 3D designs of Aker clasps,

Tribst et al. 2020 [55]

BS RPD with different materials, within $0.25,0.5$, and $0.75 \mathrm{~mm}$ undercuts

$\mathrm{Co}-\mathrm{Cr}$

Six materials:

(i) Polyamide

(ii)

Polyoxymethylene

(iii) PEEK

(iv) Gold alloy

(v) Titanium (Ti-

6Al-7Nb) Co-Cr

72 3D models of PEEK clasps

Peng et al. 2020 [63]

Yamazaki

et al. 2019

[64]

blocked-out undercut with 0.50

Co-Cr base denture with two

Mandibular

$\& 0.75 \mathrm{~mm}$ on the buccal surface

(i) PEEK

(ii) $\mathrm{Co}-\mathrm{Cr}$

thermoplastic

resin clasps

(i) Polyester

polyamide

Reddy

et al. 2016

[57]

Nakamura

et al. 2014

[58]

Mandibular

(i) 1 Aker and 1 reverse Aker

FES RPD

(ii) 1 embrasure clasp

(iii) 1 I-bar clasp

Mandibular 2 Aker clasps, with two differen

(i) $\mathrm{Co}-\mathrm{Cr}$ materials, in $0.25 \mathrm{~mm}$ undercut of the main abutment

(ii) Acetal resin

(i) I-bar clasp design could demonstrate optimal mechanical properties as long as the length of horizontal and vertical arms did not exceed $6 \mathrm{~mm}$ length

(i) The stress was concentrated at the shoulder of the circumferential clasp in all models

(ii) The highest stress was reported in CoCr with $0.75 \mathrm{~mm}$, while the lowest stress

$\sqrt{ }$ and force of was reported in polyamide, regardless of removal depths of undercuts

(iii) Polyamide showed the lowest forces of removal, followed by

polyoxymethylene, while $\mathrm{Co}-\mathrm{Cr}$ showed the highest removal force followed by titanium

(i) The maximum stress concentration was located at the base of the clasp

(ii) The stress concentration increased when the thickness of the material

increased

$\sqrt{ }$ and force of

(iii) PEEK clasp showed higher flexibility

when compared with Co-Cr clasp

(iv) PEEK clasp with a ratio of

width/thickness at the tip 2.70/1.69,

$1.50 / 1.13$, or $1.75 / 1.53$ was considered an optimal clasp to $0.5 \mathrm{~mm}$ undercut

(i) The stress was concentrated at the shoulder of the clasps but on the inner surface

$\sqrt{ } \quad \sqrt{ }$ and force of (ii) No significant differences were removal reported between the two types of resin (iii) The retention of thermoplastic clasps depends on the position and depth of undercut rather than the material itself

(i) The highest stress was reported in the Co-Cr clasp compared with the acetal $\sqrt{ }$ and force of resin removal (ii) The force of removal of acetal resin was significantly lesser than that of the $\mathrm{Co}-\mathrm{Cr}$

(i) RPI clasp shows lower stress concentration in the buccal and apical region and areas of the cortical bone supporting the abutment tooth when compared with Aker and embrasure clasps

(ii) Embrasure clasp expressed slightly lesser vertical displacement compared with RPI and Aker clasps, while RPI showed significantly lesser distal displacement followed by embrasure and Aker clasps

(i) $\mathrm{Co}-\mathrm{Cr}$

Oyar et al.

$93 \mathrm{D}$ models of the I-bar clasp of

2012 [44] three different materials and

three modified tips
$6 \mathrm{Al}-7 \mathrm{Nb}$ )

(iii) Gold alloy (i) The maximum stress concentration was located at the horizontal curvature of the clasp and was reported in the Co-Cr specimen, while the gold alloy specimen showed the minimum stress 
TABle 2: Continued.

\begin{tabular}{lllll}
\hline Authors & $\begin{array}{c}\text { Type of } \\
\text { prosthesis }\end{array}$ & $\begin{array}{l}\text { The examined independent } \\
\text { variable }\end{array}$ & $\begin{array}{l}\text { Materials used in } \\
\text { the denture }\end{array}$ & $\begin{array}{c}\text { Reported dependent } \\
\text { variable } \\
\text { Displacement } \\
\text { deflection }\end{array}$
\end{tabular} Outcome

(ii) There is a direct relationship between lengths of the horizontal arm and development of stresses in the arms of the clasp

(i) Both attachments showed similar stress distribution in the alveolar bone and PL, but with more concentration in the case of rigid attachment

Wang et al. Mandibular Rigid and nonrigid precision 2011 [67] class II attachment (ERA attachment)
$\mathrm{Ni}-\mathrm{Cr}$

(i) Reverse Aker

Aoda et al. Mandibular 2010 [59] FES RPD

Sandu et al. Maxillary 2010 [62] FES RPD

Judy 2009

[56]

FES RPD

Optimizing the width \& length of the circumferential clasp arm

Evaluation of the I-bar clasp with 6 widths \& lengths
Evaluation of round and halfround clasps with 9 diameters (from 0.5 to $1.3 \mathrm{~mm}$ ) for each

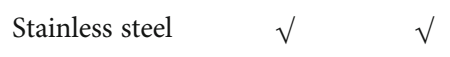

Co-Cr

$\mathrm{Co}-\mathrm{Cr}$ (ii) Compared with the rigid attachment, the nonrigid attachment resulted in higher stress in the mesial and distal end of the residual ridge when subjected to axial loads; however, the opposite was true regarding buccolingual and mesiodistal loads

(i) Reverse Aker clasp put more stress in abutment teeth compared with embrasure and back action clasps (ii) Reverse Aker provided higher stability and lesser deflection to the denture compared with embrasure and back action clasps

(i) The stress was concentrated in the inner surface of both half-round and round wires, in the part of the arm located above the height of contour of abutment teeth

(ii) Regarding the displacement, the clasp arm with half-round shape (with a diameter of $1 \mathrm{~mm}$ ) showed a similar displacement to the clasp arm with round shape (with a diameter between 0.6 and $0.7 \mathrm{~mm}$ )

The circumferential clasp with halfround shape and formula $\mathrm{W} 2 / \mathrm{W} 1=0.6$ and $T / L=0.5$ showed the least stress concentration

(i) I-bar clasp with thin and wide arm, taper 0.020-0.023, and radius of curvature of 2.75-3.00 exhibited less stress compared with the thicker or shorter ones

FES: free-end saddle; BS: bounded saddle; Co-Cr: cobalt-chromium; Ni-Cr: nickel chromium; PEEK: polyetheretherketone; W2: the width of the clasp at the tip; W1: the width of the clasp at the base; T: thickness; L: length; PL: periodontal ligaments.

shows lesser vertical displacement (tissue ward) in the same undercut depth [58]. Reverse Aker brings more load on the main abutment but also shows higher stability and lesser deflection in the prosthesis in the same undercut depth [59]. The RPI system was found to produce stress and at the same was subjected to stress and deformations as well. The stress is concentrated in the neck of the retentive arm (just before the retentive tip) and at the horizontal curvature of the clasp [44,55]. The magnitude of stress depends on many factors: the thickness and width of clasp arms, the taper and radii of the retentive arm, the shape and curvature of the horizontal approach arm, and the vertical distance between retentive tip and horizontal axis $[60,61]$. The most vulnera- ble area to stress concentration in the RPI system is located in the inner surface of the retentive clasp arm and the area just above the vertical projection of the horizontal arm [62]. To optimize the length and width of the I-bar clasp arm, a thinner and wider arm with a taper of 0.02-0.03 and radius of $2.75-3.00 \mathrm{~mm}$ was advocated to reduce the stress in the abutment tooth [61]. It was found that the optimal length of horizontal and vertical arms should not exceed $6 \mathrm{~mm}$ to optimize the biomechanical stress within the clasp [60]. More flexible materials were compared with Co-Cr to optimize the stress on the abutment in FES RPD scenarios such as gold alloys, titanium alloys, stainless clasps, PEEK, and the use of resin clasps (polyesters and polyamides) [62-65]. PEEK 
TABLE 3: Studies reporting the influence of different designs of the major connector on the stress and displacement of conventional RPD.

\begin{tabular}{|c|c|c|c|c|c|c|}
\hline Authors & $\begin{array}{l}\text { Type of } \\
\text { prosthesis }\end{array}$ & $\begin{array}{c}\text { The examined independent } \\
\text { variable }\end{array}$ & $\begin{array}{l}\text { Materials used } \\
\text { in the denture }\end{array}$ & $\begin{array}{l}\text { Repor } \\
\text { Stress }\end{array}$ & $\begin{array}{l}\text { ted dependent } \\
\text { variable } \\
\text { Displacement } \\
\text { deflection }\end{array}$ & Outcome \\
\hline
\end{tabular}

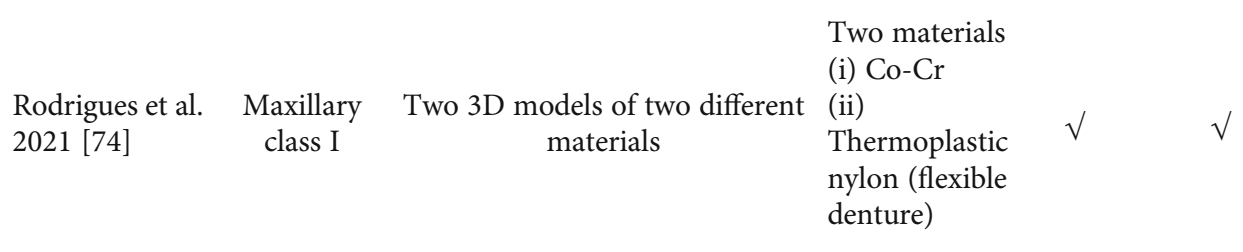

3 materials

Chen et al. Mandibular Three models for three different (i) $\mathrm{Co}-\mathrm{Cr}$

2019 [66] class I materials $\quad$ (ii) $\mathrm{Ti}$ alloy

(iii) PEEK

Five 3D models of different

Hallikerimath Maxillary

et al. 2015 [72] class II RPD

narrow, deep, and shallow)

Co-Cr $\quad-\quad$ V

Different Six 3D models of 3 different

Bhojaraju et al. scenarios of maxillary MC (PS, CPP, APPS)

2014 [69] maxillary with different scenarios of

RPD Kennedy classification

Ramakrishnan

\& Singh 2010

[71]
Maxillary

class IV
Four 3D models of U-shape PB (regular, increasing the width, adding posterior PS, and duplicating the thickness to $1 \mathrm{~mm}$ ) (i) In both models, the maximum stress has been shown on the slopes of the maxillary arch

(ii) The maximum displacement has been shown on the crest of the residual alveolar ridge (iii) The Co-Cr showed the least stress and displacement compared with nylon

(i) The lowest stress in the PDL of the abutment and framework was reported with PEEK

(ii) PEEK has exhibited the highest displacement of the ridge and mucosa

(i) The maximum distal displacement was reported in the wide and shallow palate, while maximum buccal displacements were higher in the deep palate (ii) Maximum vertical displacement was higher in the average model

(iii)The deflection was lesser in the narrow palate compared to the other palatal shapes

(i) APPS showed the lowest deflection compared with CPP and PS

(ii) For APPS, the maximum deflection was reported in the occlusal rest responding to load with anteroposterior direction and the anterior part of buccal slope regarding vertical direction (iii) For CPP, the maximum deflection has been reported in the occlusal rest regarding anteroposterior load and the buccal slope and crest of the ridge regarding vertical force

(i) The PB with a regular width showed the maximum deflection and displacement compared with the other forms

(ii) The double-thickness Ushape MC exhibited the lowest stress followed by wide U-shape MC

(iii) The highest stress on the palate and teeth has been shown in double thickness as well

(iv) The lowest stress on the palate and mucosa has been 
TABLE 3: Continued.

\begin{tabular}{|c|c|c|c|c|c|c|}
\hline Authors & $\begin{array}{l}\text { Type of } \\
\text { prosthesis }\end{array}$ & $\begin{array}{l}\text { The examined independent } \\
\text { variable }\end{array}$ & $\begin{array}{l}\text { Materials used } \\
\text { in the denture }\end{array}$ & $\begin{array}{l}\text { Repor } \\
\text { Stress }\end{array}$ & $\begin{array}{l}\text { ted dependent } \\
\text { variable } \\
\text { Displacement } \\
\text { deflection }\end{array}$ & Outcome \\
\hline $\begin{array}{l}\text { Takanashi } \\
\text { et al. } 2009 \text { [73] }\end{array}$ & $\begin{array}{l}\text { Maxillary } \\
\text { class II }\end{array}$ & $\begin{array}{l}\text { Five } 3 \mathrm{D} \text { models of different } \\
\text { palatal vaults (basic, wide, } \\
\text { narrow, deep, and shallow) }\end{array}$ & $\begin{array}{l}\text { Three } \\
\text { materials were } \\
\text { used: } \\
\text { (i) Co-Cr } \\
\text { (ii) Titanium } \\
\text { (Ti-6Al-7Nb) } \\
\text { (iii) Gold alloy } \\
\text { (type IV) }\end{array}$ & - & $\sqrt{ }$ & $\begin{array}{l}\text { reported in the scenario of wide } \\
\text { MC } \\
\text { (i) In all tested MC models, the } \\
\text { narrow model has reported the } \\
\text { lowest displacement when } \\
\text { compared with the basic, wide, } \\
\text { and shallow palates, which } \\
\text { exhibited the maximum } \\
\text { displacement } \\
\text { (ii) In the deep palate model, the } \\
\text { Ti MC with a width of } 11 \text { mm } \\
\text { and gold MC with a width of } \\
9 \text { mm showed similar } \\
\text { displacement to the basic model }\end{array}$ \\
\hline $\begin{array}{l}\text { Eto et al. } 2002 \\
{[70]}\end{array}$ & $\begin{array}{l}\text { Maxillary } \\
\text { class II RPD }\end{array}$ & $\begin{array}{l}\text { In } 13 \text { 3D models, } 11 \text { of them } \\
\text { show PS MC with different AP } \\
\text { widths at the midlines, } 1 \text { design } \\
\text { for APPB, and lastly, horseshoe } \\
\text { PS with } 7 \mathrm{~mm}\end{array}$ & $\mathrm{Co}-\mathrm{Cr}$ & - & $\sqrt{ }$ & $\begin{array}{l}\text { (i) The maximum displacement } \\
\text { has been shown in all models at } \\
\text { the posterior edge of the saddle } \\
\text { (ii) Vertical and buccal } \\
\text { displacements were inversely } \\
\text { proportional to the width of the } \\
\text { major connector. As the major } \\
\text { connector increased, the } \\
\text { displacement decreased } \\
\text { (iii) APPB and wide PS exhibited } \\
\text { the lowest buccal displacement } \\
\text { compared with horseshoes, } \\
\text { which showed the maximum } \\
\text { displacement (least rigidity) }\end{array}$ \\
\hline
\end{tabular}

FES: free-end saddle; AP: anteroposterior; PS: palatal strap; APPS: anteroposterior palatal strap; APPB: anteroposterior palatal bar; CPP: complete palatal plate; MC: major connector; Ti: titanium.

was proven as an attractive option to replace the $\mathrm{Co}-\mathrm{Cr}$ due to the minimum stress on the PL of the abutments and at the same time showed adequate retention $[63,66]$. To optimize the retention of the PEEK clasp in a 0.01 -inch undercut, the ratio width/thickness at the tip shall be $1.50 / 1.13$, $1.75 / 1.53$, or $2.70 / 1.69$ [63].

Rigid and nonrigid attachments are considered efficient retainers to FES RPD with no visible metal components. Use of nonrigid attachment results in less stress in the main abutment but on the other hand brings more stress to the supporting ridge. The concentration of the stress in the ridge was obvious in the mesial and distal area of the saddle [67].

3.3.2. Occlusal Rest Position. The occlusal rest position shows a role in stress distribution in abutment teeth and RPD framework. Putting the occlusal rest on the distal side of the terminal abutment was found to improve the stress distribution in these teeth and stiffen the metal frameworks and acrylic resin denture bases by $66 \%$ when compared with the occlusal rest placed on the mesial side of the same abutment [68].

3.3.3. Design of Major Connectors. While the retentive arm of retainers should be fabricated from flexible materials, major connectors should be rigid to provide an equal distribution of load and prevent stress concentration in supporting structures. The prosthesis with a highly rigid major connector is associated with less deflection during function [69]. The deflection of the prosthesis results in unequal distribution of the stress in the underlying structures, which leads to inflammation and resorption of the residual ridge [69]. The stress developed in supporting structures depends on the material of fabrication, design and thickness of the used major connector, and the shape of the palate [66]. The anteroposterior palatal strap design was found to be the most rigid design compared with different designs such as complete palatal plate, posterior palatal strap, and, lastly, horseshoe-shaped major connector, which showed the lowest rigidity $[69,70]$. To increase the rigidity and to reduce the internal stres in of horseshoe-shaped major connectors, a double thickness was advocated. This modification, however, can deliver higher stress on the underlying mucosae and PL [71]. The shape of the palate also influences the stress and displacement of the major connector $[72,73]$. The narrow palate shows the least displacement in the major connector comparing the wide and shallow palate $[72,73]$. The flexible framework materials are always associated with less stress in the major connector, but more displacement on the ridge is 
TABLE 4: Studies reporting the biomechanical stress and displacement in implant-assisted removable partial denture with different designs.

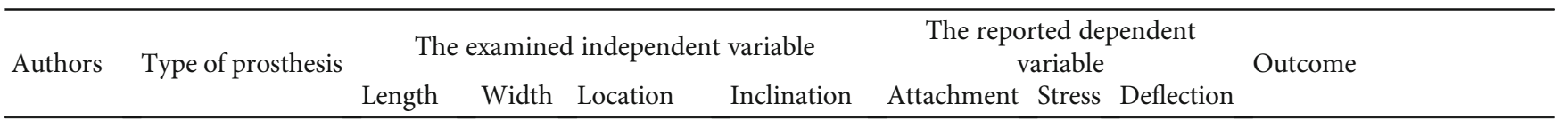

\begin{tabular}{|c|c|c|c|c|c|c|c|c|c|}
\hline $\begin{array}{l}\text { Tribst } \\
\text { et al. } 2020 \\
{[55]}\end{array}$ & $\begin{array}{l}\text { Four } 3 \mathrm{D} \text { models } \\
\text { of conventional } \\
\text { and ISRPD class } \\
\text { II mod } 2 \text { with } 3 \\
\text { different designs }\end{array}$ & - & - & $\begin{array}{l}\text { (i) M1 at } \\
\text { the } 1^{\text {st }} \\
\text { molar } \\
\text { (ii) } \mathrm{M} 2 \text { at } \\
\text { the } 2^{\text {nd }} \\
\text { molar } \\
\text { (iii) M3 } 2 \\
\text { implants at } \\
\text { the } 1^{\text {st }} \text { and } \\
2^{\text {nd }} \text { molars }\end{array}$ & & & & & $\begin{array}{l}\text { (i) The highest stress } \\
\text { concentration in the } \\
\text { implant has been reported } \\
\text { in the implants of M2 } \\
\text { followed by M3 } \\
\text { (ii) The implant in the } 1^{\text {st }} \\
\text { molar region received less } \\
\text { stress as in M1 and M3 }\end{array}$ \\
\hline $\begin{array}{l}\text { Messias } \\
\text { et al. } 2019 \\
{[76]}\end{array}$ & $\begin{array}{l}\text { Two 3D models of } \\
\text { mandibular class I } \\
\text { IARPD in } 2 \\
\text { different locations }\end{array}$ & - & - & $\begin{array}{l}\text { (i) M1 } \\
\text { implants } \\
\text { located at } \\
\text { the } \\
\text { premolar } \\
\text { area } \\
\text { (ii) M2 at } \\
\text { the } \\
\text { premolar } \\
\text { area }\end{array}$ & - & - & $\sqrt{ }$ & - & $\begin{array}{l}\text { (i) The implant located in } \\
\text { the premolar area } \\
\text { exhibited the highest } \\
\text { displacement in the } \\
\text { posterior region, while the } \\
\text { opposite happened when } \\
\text { the implant was located in } \\
\text { the molar area } \\
\text { (ii) The stress was more } \\
\text { concentrated in the part of } \\
\text { the major connector next } \\
\text { to abutment teeth } \\
\text { (iii) More stress on the } \\
\text { posterior part of the saddle } \\
\text { was shown when the } \\
\text { implant was located in the } \\
\text { premolar area }\end{array}$ \\
\hline $\begin{array}{l}\text { Ortiz- } \\
\text { Puigpelat } \\
\text { et al. } 2019 \\
\text { [77] }\end{array}$ & $\begin{array}{l}\text { Two 3D models of } \\
\text { mandibular class I } \\
\text { IARPD in } 2 \\
\text { different locations }\end{array}$ & - & - & $\begin{array}{l}\text { Three } \\
\text { different } \\
\text { locations } \\
\text { (i) M1 at } \\
\text { the } 2^{\text {nd }} \\
\text { molar } \\
\text { (ii) M2 at } \\
\text { the } 1^{\text {st }} \\
\text { molar } \\
\text { (iii) M3 at } \\
\text { the } 2^{\text {nd }} \\
\text { premolar }\end{array}$ & - & - & $\sqrt{ }$ & - & $\begin{array}{l}\text { When the implant was } \\
\text { located in the } 1 \text { st molar } \\
\text { area, less displacement } \\
\text { and minimum stress at the } \\
\text { implant and the metal } \\
\text { framework were reported }\end{array}$ \\
\hline $\begin{array}{l}\text { Andrei } \\
\text { et al. } 2015 \\
{[43]}\end{array}$ & $\begin{array}{l}\text { One model for } \\
\text { conventional and } \\
\text { IARPD for Co-Cr } \\
\text { mandibular class I }\end{array}$ & - & - & $\begin{array}{l}2 \text { implants } \\
\text { were placed } \\
\text { bilaterally } \\
\text { in the } 2^{\text {nd }} \\
\text { molar area }\end{array}$ & - & - & $\sqrt{ }$ & $\sqrt{ }$ & $\begin{array}{l}\text { (i) In the conventional } \\
\text { RPD, the maximum stress } \\
\text { was reported at the } \\
\text { anterior (premolar) and } \\
\text { posterior ( } 2^{\text {nd }} \text { molar) areas } \\
\text { (ii) There was a reduction } \\
\text { in the maximum stress at } \\
\text { the same area in IARPD } \\
\text { compared with the } \\
\text { conventional RPD } \\
\text { (iii) The lateral } \\
\text { displacement was high at } \\
\text { the distal edge of both }\end{array}$ \\
\hline
\end{tabular}


TABle 4: Continued.

\begin{tabular}{|c|c|c|c|c|c|c|c|c|}
\hline \multirow[t]{2}{*}{ Authors } & \multirow[t]{2}{*}{ Type of prosthesis } & \multicolumn{4}{|c|}{ The examined independent variable } & \multicolumn{3}{|c|}{$\begin{array}{l}\text { The reported dependent } \\
\text { variable }\end{array}$} \\
\hline & & Length & Width & Location & Inclination & Attachment & Stress & Deflection \\
\hline $\begin{array}{l}\text { Memari } \\
\text { et al. } 2014 \\
{[17]}\end{array}$ & $\begin{array}{l}\text { Three } 3 \mathrm{D} \text { models, } \\
\text { one for class II } \\
\text { IARPD in } 3 \\
\text { different locations }\end{array}$ & - & - & $\begin{array}{l}\text { (i) } \mathrm{M} 1 \text { at } \\
\text { the } 2^{\text {nd }} \\
\text { molar area } \\
\text { (ii) } \mathrm{M} 2 \text { at } \\
\text { the } 1^{\text {st }} \\
\text { molar area } \\
\text { (iii) M3 at } \\
\text { the } 2^{\text {nd }} \\
\text { premolar } \\
\text { area }\end{array}$ & - & - & $\sqrt{ }$ & - \\
\hline
\end{tabular}

prostheses but with a

higher value in the conventional RPD than in IARPD

As the implant was placed more anteriorly, more stress was concentrated in the terminal abutment, reaching its maximum value when the implant was located next to the terminal abutment

(i) In all IARPD designs, there was a clear diminish in the displacement when compared with the conventional RPD (ii) In IARPD, the lowest displacement has been

The implant location: Five models: (i) Natural

Cunha

et al. 2008

(ii) Conventional

[80] (i) Distal

(2nd molar)

(ii) Middle

(1st molar)

(iii) Mesial

(1st

premolar) exhibited in an implant located in the middle of the residual ridge and then the distal area of the ridge, while the mesial location of the implant showed the lowest stress in the terminal abutment (iii) The mesially placed implant showed the highest stress value in the internal thread of the implant followed by the middle and then the distal area, which showed the least stress

(i) The stress on the terminal abutment was the least with an implant of $10 \times 3.5$ and then $10 \times 3$ in the 1st molar area, compared with implants of $10 \times 3.5$ and $10 \times 3$, at the 2nd molar area

(ii) The highest stress has been recorded in the implant of $10 \times 3$ and located in the $2^{\text {nd }}$ molar area, while the lowest stress has been recorded in the implant of $10 \times 3$ and 
TABLE 4: Continued.

\begin{tabular}{|c|c|c|c|c|c|c|c|c|c|}
\hline \multirow[t]{2}{*}{ Authors } & \multirow[t]{2}{*}{ Type of prosthesis } & \multicolumn{4}{|c|}{ The examined independent variable } & \multicolumn{3}{|c|}{$\begin{array}{l}\text { The reported dependent } \\
\text { variable }\end{array}$} & \multirow[t]{2}{*}{ Outcome } \\
\hline & & Length & Width & Location & Inclination & Attachment & Stress & Deflection & \\
\hline $\begin{array}{l}\text { Fayaz } \\
2015[81]\end{array}$ & $\begin{array}{l}\text { Six 3D models of } \\
\text { IARPD with two } \\
\text { lengths and } 3 \\
\text { different } \\
\text { inclinations }\end{array}$ & $\begin{array}{l}\text { (i) } \mathrm{M} 1-3 \\
(7 \mathrm{~mm}) \\
\mathrm{M} 4-6 \\
(10 \mathrm{~mm})\end{array}$ & $4 \mathrm{~mm}$ & $\begin{array}{l}1^{\text {st }} \text { molar } \\
\text { area }\end{array}$ & $\begin{array}{l}\text { (i) } \mathrm{M} 1-3 \text { at } \\
0^{\circ}, 10^{\circ} \text {,and } \\
15^{\circ} \\
\mathrm{M} 4-6 \text { at } 0^{\circ} \text {, } \\
10^{\circ} \text {, and } 15^{\circ} \text {, } \\
\text { respectively }\end{array}$ & - & $\sqrt{ }$ & - & $\begin{array}{l}\text { located in the } 1 \text { st molar } \\
\text { area } \\
\text { (i) Increasing the } \\
\text { inclination of the implant } \\
\text { has shown increase in the } \\
\text { stress in the implant to } \\
\text { reach the maximum in } \\
\text { M6, while the stress in the } \\
\text { terminal abutment } \\
\text { decreased to the minimum } \\
\text { (ii) As the length of the } \\
\text { implant increased, the } \\
\text { stress on the abutment } \\
\text { decreased }\end{array}$ \\
\hline $\begin{array}{l}\text { de Freitas } \\
\text { Santos } \\
\text { et al. } 2011 \\
\text { [82] }\end{array}$ & $\begin{array}{l}\text { Six } 3 D \text { models of } \\
\text { natural, } \\
\text { conventional, and } \\
\text { IARPD } \\
\text { mandibular class } \\
\text { II with } 4 \text { different } \\
\text { angles }\end{array}$ & - & - & $\begin{array}{l}2^{\text {nd }} \text { molar } \\
\text { region }\end{array}$ & $\begin{array}{l}4 \text { models } \\
\text { with } \\
\text { different } \\
\text { inclinations } \\
\text { were used: } \\
\left(0^{\circ}, 5^{\circ}, 15^{\circ} \text {, }\right. \\
\left.\text { and } 30^{\circ}\right) \text { in a } \\
\text { mesial } \\
\text { direction }\end{array}$ & - & $\sqrt{ }$ & $\sqrt{ }$ & $\begin{array}{l}\text { (i) Adding an implant to } \\
\text { assist RPD led to a } \\
\text { significant reduction in the } \\
\text { displacement of the } \\
\text { prostheses } \\
\text { (ii) The stress around the } \\
\text { apex of the terminal } \\
\text { abutment in all models } \\
\text { with implants has shown } \\
\text { better distribution in } 0^{\circ} \\
\text { and } 5^{\circ} \text { compared to } 15^{\circ} \\
\text { and } 30^{\circ} \text {, which showed the } \\
\text { highest stress }\end{array}$ \\
\hline
\end{tabular}

M: model; IARPD: implant-assisted removable partial denture.

recorded $[66,73,74]$. Table 3 shows that the studies evaluated the influences of major connectors on the stress and deflection of RPDs. Table 3 shows also the lack of literature in evaluation of stress developed in the different designs of mandibular major connectors.

3.3.4. Splinting of the Abutment Teeth. Teeth with reduced periodontal support are considered inadequate abutments for retention and support of RPDs, especially RPDs with distal extension scenarios. However, splinting two or more reduced periodontally supported teeth was beneficial for adequate stress distribution and reduction of the anterior displacement of these teeth. Splinting more than three teeth around the arch was more beneficial as it can provide a curve for resistance to the buccolingual displacement [75].

3.3.5. Use of the Implant Approach. Implant-assisted RPDs were advocated for FES scenarios to provide a substantial increase in retention of the RPD as well as reduction of the stress in the abutments and residual ridges. According to the implant-assisted RPD concept, the implant and surrounding bone (especially the cancellous) receive the majority of the stress, while abutments receive minimal stress and the displacement of the prosthesis becomes minimal [21, 47-49]. On the other hand, the acrylic base of the prosthesis over the abutment of the implant receives a significant amount of stress, which may lead to the frequent fractures of this part of acrylic around the attachment. This is mainly due to the mismatch of the distribution of stress between the acrylic bases and the base metal framework as the stresses developed in the metal frameworks mainly concentrated in the major and minor connectors away from the attachment area, while the occlusal load transfers directly to the acrylic materials around the attachment [49].

The stress developed on the abutment, implants, and denture base materials varies according to the implant location, inclination, diameter, and type of applied load. Table 4 shows the influences of implant designs on the development of stress and displacement.

\subsection{Factors Affecting Stress Developed in Implant- Assisted RPDs}

3.4.1. Implant Location. Implant locations were found to have direct influences on the development of stress in abutments and residual ridge. When the implant is placed more anteriorly (the premolar area), the stress on the implant became maximum, the stress on the abutment teeth became minimum, and the displacement distally became maximum. On the other hand, when the implant is placed more posteriorly (the $2^{\text {nd }}$ molar area), the stress on the abutment teeth becomes considerably high and more displacement is 
reported at the mesial side of the residual ridge. Placement of the implant in the first molar area has been proven to have the lowest stress in the implant, lowest stress in abutment teeth, and lowest stress in the distal side of the residual ridge $[17,55,76-79]$.

3.4.2. Length and Diameter of the Implant. The length and diameter of the implant influence the displacement and stress in abutment teeth, denture supporting structures, and bone surrounding the implant. Long implants were found to decrease the stresses in abutments and minimize the stress in the surrounding bone, especially the cancellous one [81]. Similarly, the wide implants were found to decrease the displacement of the prostheses, decrease the stresses in abutments, and minimize the stress in both cortical and cancellous bone [79].

3.4.3. Implant Angulation. Different angulations of implants were evaluated to estimate their influences on the development of stress in abutments and implants [81, 82]. The inclinations of the implant result in the improvement of stress in abutment teeth but increase it on the bone surrounding the implant to reach its maximum extent with angulation of $15^{\circ}$ [81] and $30^{\circ}$ [82].

Even though the FEA has been used in the estimation of stresses in RPDs for 20 years, still lack of FEA studies in the literature exists. The lack is mainly regarding the estimation of stresses in different designs of RPDs (especially the bounded and anterior edentulism), different designs of mandibular major connectors, use of short and narrow implants, and use of different systems of attachments.

\section{Conclusion}

Within the limitation of the present study, the following can be concluded:

(1) Implants in implant-assisted RPDs receive the majority of the dynamic load. The magnitude of the load decreases with zero or minimal angulations of the implant, using long and wide implants, and when the implant is placed in the first molar area

(2) Stress in FES RPDs are concentrated in the shoulder of the clasp, the minor connector of the mesial rest, and the part of major connector next to the terminal abutment

(3) Clasps with flexible arms decrease the stress in abutment teeth, while the rigid major connector decreases the displacement and stresses in the residual ridge

(4) The distal occlusal rest stiffens the framework and decreases the stress on the terminal abutment

(5) Resilient attachments put less stress in abutments but increase the stress in the residual ridge, especially the posterior part of the saddle

(6) A lack of FEA studies covering many aspects of different designs of RPDs exists

\section{Data Availability}

All data are available within the manuscript.

\section{Conflicts of Interest}

There are no conflicts of interest.

\section{Authors' Contributions}

All authors had the same contribution in data collection, annotation, and manuscript preparation in this study.

\section{References}

[1] M. A. Mousa, E. Lynch, M. G. Sghaireen, A. M. Zwiri, and O. A. Baraka, "Influence of time and different tooth widths on masticatory efficiency and muscular activity in bilateral free-end saddles," International Dental Journal, vol. 67, no. 1, pp. 29-37, 2017.

[2] M. A. Mousa, S. Patil, and E. Lynch, "Masticatory efficiency and muscular activity in removable partial dental prostheses with different cusp angles," The Journal of Prosthetic Dentistry, vol. 117, no. 1, pp. 55-60, 2017.

[3] B. Shrestha, B. B. Basnet, and G. Adhikari, "A questionnaire study on the impact on oral health-related quality of life by conventional rehabilitation of edentulous patient," BDJ Open, vol. 6, no. 1, 2020.

[4] S. D. Campbell, L. Cooper, H. Craddock et al., "Removable partial dentures: the clinical need for innovation," The Journal of Prosthetic Dentistry, vol. 118, no. 3, pp. 273-280, 2017.

[5] L. F. Cooper, "The current and future treatment of edentulism," Journal of Prosthodontics, vol. 18, no. 2, pp. 116-122, 2009.

[6] P. Preshaw, A. Walls, N. Jakubovics, P. Moynihan, N. Jepson, and Z. Loewy, "Association of removable partial denture use with oral and systemic health," Journal of Dentistry, vol. 39, no. 11, pp. 711-719, 2011.

[7] E. P. Pellizzer, D. A. F. Almeida, R. M. Falcón-Antenucci, D. M. I. K. Sánchez, P. R. J. Zuim, and F. R. Verri, "Prevalence of removable partial dentures users treated at the Aracatuba Dental School - UNESP," Gerodontology, vol. 29, no. 2, pp. 140-144, 2012.

[8] J. G. Steele and I. O'Sullivan, Executive summary: Adult Dental Health Survey, NHS Health and Social Care Information Centre, 2009, http://contentdigitalnhsuk/catalogue/PUB01086/ adul-dent-heal-surv-summ-them-exec-2009-rep2pdf.

[9] J. G. Steele, E. T. Treasure, I. O'Sullivan, J. Morris, and J. J. Murray, "Adult Dental Health Survey 2009: transformations in British oral health 1968-2009," British Dental Journal, vol. 213, no. 10, pp. 523-527, 2012.

[10] C. D. Lynch, "Successful removable partial dentures," Dental Update, vol. 39, no. 2, pp. 118-126, 2012.

[11] B. Benso, A. C. Kovalik, J. H. Jorge, and N. H. Campanha, "Failures in the rehabilitation treatment with removable partial dentures," Acta Odontologica Scandinavica, vol. 71, no. 6, pp. 1351-1355, 2013.

[12] H. N. H. Alsharif, K. K. Ganji, M. K. Alam et al., "Periodontal Clinical Parameters as a Predictor of Bite Force: A Cross- Sectional Study," BioMed Research International, vol. 2021, Article ID 5582946, 8 pages, 2021. 
[13] M. Bhathal, J. Batra, G. Attresh, and S. Sambyal, "A review on stresses-induced by removable partial dentures," International Journal of Contemporary Dental \& Medical Reviews, vol. 2015, 2015.

[14] L. Costa, C. do Nascimento, V. O. P. de Souza, and V. Pedrazzi, "Microbiological and clinical assessment of the abutment and non-abutment teeth of partial removable denture wearers," Archives of Oral Biology, vol. 75, pp. 74-80, 2017.

[15] R. C. S. Rodrigues, A. C. L. Faria, A. P. Macedo, M. G. C. de Mattos, and R. F. Ribeiro, "Retention and stress distribution in distal extension removable partial dentures with and without implant association," Journal of Prosthodontic Research, vol. 57, no. 1, pp. 24-29, 2013.

[16] J. D. Jones, I. Turkyilmaz, and L. T. Garcia, "Removable partial dentures-treatment now and for the future," Texas Dental Journal, vol. 127, p. 365, 2010.

[17] Y. Memari, A. Geramy, A. Fayaz, S. Rezvani Habib Abadi, and Y. Mansouri, "Influence of implant position on stress distribution in implant-assisted distal extension removable partial dentures: a 3D finite element analysis," Journal of Dentistry, vol. 11, no. 5, pp. 523-530, 2014.

[18] R. G. Bassetti, M. A. Bassetti, and J. Kuttenberger, "Implantassisted removable partial denture prostheses: a critical review of selected literature," The International Journal of Prosthodontics, vol. 31, no. 3, pp. 287-302, 2018.

[19] M. G. Sghaireen, K. C. Srivastava, D. Shrivastava et al., "A CBCT based three-dimensional assessment of mandibular posterior region for evaluating the possibility of bypassing the inferior alveolar nerve while placing dental implants," Diagnostics, vol. 10, no. 6, p. 406, 2020.

[20] M. Sato, Y. Suzuki, D. Kurihara, H. Shimpo, and C. Ohkubo, "Effect of implant support on mandibular distal extension removable partial dentures: relationship between denture supporting area and stress distribution," Journal of Prosthodontic Research, vol. 57, no. 2, pp. 109-112, 2013.

[21] J. W. Eom, Y. J. Lim, M. J. Kim, and H. B. Kwon, "Threedimensional finite element analysis of implant-assisted removable partial dentures," The Journal of Prosthetic Dentistry, vol. 117, no. 6, pp. 735-742, 2017.

[22] D. M. Daubert, B. F. Weinstein, S. Bordin, B. G. Leroux, and T. F. Flemmig, "Prevalence and predictive factors for periimplant disease and implant failure: a cross-sectional analysis," Journal of Periodontology, vol. 86, no. 3, pp. 337-347, 2015.

[23] S. Vervaeke, B. Collaert, J. Cosyn, E. Deschepper, and H. De Bruyn, "A multifactorial analysis to identify predictors of implant failure and peri-implant bone loss," Clinical Implant Dentistry and Related Research, vol. 17, pp. e298-e307, 2015.

[24] S. Raikar, P. Talukdar, S. Kumari, S. K. Panda, V. M. Oommen, and A. Prasad, "Factors affecting the survival rate of dental implants: a retrospective study," Journal of International Society of Preventive \& Community Dentistry, vol. 7, no. 6, pp. 351-355, 2017.

[25] S. Cakarer, F. Selvi, T. Can et al., "Investigation of the risk factors associated with the survival rate of dental implants," Implant Dentistry, vol. 23, no. 3, pp. 328-333, 2014.

[26] O. Boboeva, T. G. Kwon, J. W. Kim, S. T. Lee, and S. Y. Choi, "Comparing factors affecting dental-implant loss between age groups: a retrospective cohort study," Clinical Implant Dentistry and Related Research, vol. 23, no. 2, pp. 208-215, 2021.

[27] A. B. Carr and D. T. Brown, McCracken's Removable Partial Prosthodontics-e-Book, Elsevier Health Sciences, 2010.
[28] R. D. Phoenix, D. R. Cagna, and C. F. DeFreest, Stewart's clinical removable partial prosthodontics, Quintessence Chicago, 2003.

[29] W. G. Assunção, V. A. Ricardo Barão, L. F. Tabata, É. A. Gomes, J. A. Delben, and P. H. dos Santos, "Biomechanics studies in Dentistry," Journal of Craniofacial Surgery, vol. 20, no. 4, pp. 1173-1177, 2009.

[30] A. A. Pesqueira, M. C. Goiato, H. G. Filho et al., "Use of stress analysis methods to evaluate the biomechanics of oral rehabilitation with implants," Journal of Oral Implantology, vol. 40, no. 2, pp. 217-228, 2014.

[31] K. Ramesh and S. Sasikumar, "Digital photoelasticity: recent developments and diverse applications," Optics and Lasers in Engineering, vol. 135, p. 106186, 2020.

[32] J. P. M. Tribst, A. M. O. Dal Piva, and A. L. S. Borges, "Biomechanical tools to study dental implants: a literature review," Brazilian Dental Science, vol. 19, no. 4, pp. 5-11, 2016.

[33] S. Trivedi, "Finite element analysis: a boon to dentistry," Journal of Oral Biology and Craniofacial Research, vol. 4, no. 3, pp. 200-203, 2014.

[34] W. M. S. al Qahtani and M. I. el-Anwar, "Advanced computational methods in bio-mechanics," Open Access Macedonian Journal of Medical Sciences, vol. 6, no. 4, pp. 742-746, 2018.

[35] M. Mousa, N. Jamayet, E. Lynch, and A. Husein, "Biomechanical stress in removable complete dental prostheses: a narrative review of finite element studies," Journal of International Oral Health, vol. 12, pp. 413-419, 2020.

[36] H. Suenaga, J. N. Chen, W. Li et al., "Validate mandible finite element model under removable partial denture (RPD) with In Vivo pressure measurement," Applied Mechanics and Materials, vol. 553, pp. 322-326, 2014.

[37] M. A. Mousa, J. Y. Abdullah, N. B. Jamayet, M. K. Alam, and A. Husein, "Biomechanical stress in obturator prostheses: a systematic review of finite element studies," BioMed Research International, vol. 2021, Article ID 6419774, 12 pages, 2021.

[38] S. Mohammed and H. Desai, "Basic concepts of finite element analysis and its applications in dentistry: an overview," Journal of Oral Hygiene \& Health, vol. 2, no. 5, 2014.

[39] T. H. Farook, M. A. Mousa, and N. B. Jamayet, "Method to control tongue position and open source image segmentation for cone- beam computed tomography of patients with large palatal defect to facilitate digital obturator design," Journal of Oral and Maxillofacial Surgery, Medicine, and Pathology, vol. 32, no. 1, pp. 61-64, 2020.

[40] R. Kanbara, Y. Nakamura, K. T. Ochiai, T. Kawai, and Y. Tanaka, "Three-dimensional finite element stress analysis: the technique and methodology of non-linear property simulation and soft tissue loading behavior for different partial denture designs," Dental Materials Journal, vol. 31, no. 2, pp. 297 308, 2012.

[41] A. A. Mahmoud, N. Wakabayashi, and H. Takahashi, "Prediction of permanent deformation in cast clasps for denture prostheses using a validated nonlinear finite element model," Dental Materials, vol. 23, no. 3, pp. 317-324, 2007.

[42] T. Ohashi, Y. Sato, T. Sasaki, H. Itoh, and M. Sato, "Prediction of stress distribution in mandibular bone treated with distalextension partial denture using finite element analysis," Journal of the Japanese Society for Experimental Mechanics, vol. 6, pp. 269-274, 2006.

[43] O. Andrei, C. Dăguci, M. Țierean, T. Farcaşiu, C. Farcaşiu, and L. Tănăsescu, "Compared stress levels of removable partial 
dentures with attachments with and without distal implants-a finite element analysis," in 2015 E-Health and Bioengineering Conference (EHB), Iasi, Romania, 2015.

[44] P. Oyar, C. Soyarslan, G. Can, and E. Demirci, "Finite element analysis of stress distribution on modified retentive tips of bar clasp," Computer Methods in Biomechanics and Biomedical Engineering, vol. 15, no. 6, pp. 609-613, 2012.

[45] L. Sandu, N. Faur, and C. Bortun, "Finite element analysis of stress distribution in the cast clasps, direct retainers of a removable partial denture," Timisoara Medical Journal, vol. 53, pp. 264-266, 2003.

[46] L. Sandu, N. Faur, and C. Bortun, "Finite element stress analysis and fatigue behavior of cast circumferential clasps," The Journal of Prosthetic Dentistry, vol. 97, no. 1, pp. 39-44, 2007.

[47] F. R. Verri, E. P. Pellizzer, J. A. Pereira, P. R. J. Zuim, and J. F. Santiago Júnior, "Evaluation of bone insertion level of support teeth in class I mandibular removable partial denture associated with an osseointegrated implant: a study using finite element analysis," Implant Dentistry, vol. 20, no. 3, pp. 192201, 2011.

[48] C. M. Rocha and S. M. Arndt, "Bone remodeling response during mastication on free-end removable prosthesis-a 3D finite element analysis," in SIMULIA Customer Conference, 2010.

[49] R. Shahmiri, J. M. Aarts, V. Bennani, R. Das, and M. V. Swain, "Strain distribution in a Kennedy class I implant assisted removable partial denture under various loading conditions," International Journal of Dentistry, vol. 2013, 11 pages, 2013.

[50] Y. Liu, Y.-N. Zhang, K. Sasaki, and X.-D. Chen, "Influence of location of osseointegrated implant on stress distribution in implant supported longitudinal removable partial dentures: 3dimensional finite element analysis," International Journal of Clinical and Experimental Medicine, vol. 12, pp. 10399-10410, 2019.

[51] V. Patrnogić, A. Todorović, M. Šćepanović, K. Radović, J. Vesnić, and A. Grbović, "Free-end saddle length influence on stress level in unilateral complex partial denture abutment teeth and retention elements," Vojnosanitetski Pregled, vol. 70, no. 11, pp. 1015-1022, 2013.

[52] R. Shahmiri and R. Das, "Finite element analysis of implantassisted removable partial denture attachment with different matrix designs during bilateral loading," The International Journal of Oral \& Maxillofacial Implants, vol. 31, no. 5, pp. e116-e127, 2016.

[53] R. Shahmiri and R. Das, "Finite element analysis of implantassisted removable partial dentures: framework design considerations," The Journal of Prosthetic Dentistry, vol. 118, no. 2, pp. 177-186, 2017.

[54] T. Nogawa, M. Saito, N. Murashima, Y. Takayama, and A. Yokoyama, "Influence of rigidity of retainers on dynamic behavior of implant-supported removable partial dentures," International Journal of Implant Dentistry, vol. 6, no. 1, pp. 60-69, 2020.

[55] J. P. M. Tribst, A. M. de Oliveira Dal Piva, A. L. S. Borges et al., "Effect of different materials and undercut on the removal force and stress distribution in circumferential clasps during direct retainer action in removable partial dentures," Dental Materials, vol. 36, no. 2, pp. 179-186, 2020.

[56] H. Judy, "Studying the effect of circumferential clasp arm design on stress distribution using three-dimensional finite element analysis," MDJ, vol. 6, pp. 55-60, 2009.

[57] J. C. Reddy, S. B. Chintapatla, N. K. Srikakula et al., "Comparison of retention of clasps made of different materials using three-dimensional finite element analysis," Journal of Clinical and Diagnostic Research: JCDR, vol. 10, p. ZC13, 2016.

[58] Y. Nakamura, R. Kanbara, K. T. Ochiai, and Y. Tanaka, “A finite element evaluation of mechanical function for 3 distal extension partial dental prosthesis designs with a 3dimensional nonlinear method for modeling soft tissue," The Journal of Prosthetic Dentistry, vol. 112, no. 4, pp. 972-980, 2014.

[59] K. Aoda, I. Shimamura, Y. Tahara, and K. Sakurai, "Retainer design for unilateral extension base partial removable dental prosthesis by three-dimensional finite element analysis," Journal of Prosthodontic Research, vol. 54, no. 2, pp. 84-91, 2010.

[60] R. Richert, A. A. Alsheghri, O. Alageel et al., "Analytical model of I-bar clasps for removable partial dentures," Dental Materials, vol. 37, no. 6, pp. 1066-1072, 2021.

[61] Y. Sato, K. Tsuga, Y. Abe, S. Asahara, and Y. Akagawa, "Finite element analysis on preferable I-bar clasp shape," Journal of Oral Rehabilitation, vol. 28, no. 5, pp. 413-417, 2001.

[62] L. Sandu, F. Topală, and S. Porojan, "Stress distribution in retentive arms of combination clasps used on premolars," Journal of Applied Biomaterials and Biomechanics, vol. 8, no. 2, pp. 76-81, 2010.

[63] T.-Y. Peng, Y. Ogawa, H. Akebono, S. Iwaguro, A. Sugeta, and S. Shimoe, "Finite-element analysis and optimization of the mechanical properties of polyetheretherketone (PEEK) clasps for removable partial dentures," Journal of Prosthodontic Research, vol. 64, no. 3, pp. 250-256, 2020.

[64] T. Yamazaki, N. Murakami, S. Suzuki et al., "Influence of block-out on retentive force of thermoplastic resin clasps: an in vitro experimental and finite element analysis," Journal of Prosthodontic Research, vol. 63, no. 3, pp. 303-308, 2019.

[65] M. Bahrami, B. Shakeri, and M. Memarian, "Investigating the stress distribution applied to edentulous ridge from polyamide and cobalt-chrome removable-partial-dentures using threedimensional finite-element-analysis," Journal of Dentomaxillofacial, vol. 9, pp. 1-8, 2020.

[66] X. Chen, B. Mao, Z. Zhu et al., "A three-dimensional finite element analysis of mechanical function for 4 removable partial denture designs with 3 framework materials: CoCr, Ti-6Al4V alloy and PEEK," Scientific Reports, vol. 9, pp. 1-10, 2019.

[67] H.-y. Wang, Z. Y-m, D. Yao, and C. J-h, "Effects of rigid and nonrigid extracoronal attachments on supporting tissues in extension base partial removable dental prostheses: a nonlinear finite element study," The Journal of Prosthetic Dentistry, vol. 105, no. 5, pp. 338-346, 2011.

[68] R. Shahmiri, R. Das, J. M. Aarts, and V. Bennani, "Finite element analysis of an implant-assisted removable partial denture during bilateral loading: occlusal rests position," The Journal of Prosthetic Dentistry, vol. 112, no. 5, pp. 1126-1133, 2014.

[69] N. Bhojaraju, J. Srilakshmi, and G. Vishwanath, "Study of deflections in maxillary major connectors: a finite element analysis," The Journal of Indian Prosthodontic Society, vol. 14, no. 1, pp. 50-60, 2014.

[70] M. Eto, N. Wakabayashi, and T. Ohyama, "Finite element analysis of deflections in major connectors for maxillary RPDs," The International Journal of Prosthodontics, vol. 15, no. 5, pp. 433-438, 2002.

[71] H. Ramakrishnan and R. G. Singh, "Three-dimensional finite element analysis of the stress distribution pattern in the design modifications of U-shaped palatal major connector," Indian Journal of Dental Research, vol. 21, no. 4, pp. 506-511, 2010. 
[72] R. Hallikerimath, H. D. Mallikarjun, V. Patil, and V. S. Kumar, "Evaluation of deflection in single palatal strap major connector as influenced by different shapes of palatal vault: a threedimensional finite element study," Journal of International Oral Health, vol. 7, p. 53, 2015.

[73] T. Takanashi, I. Shimamura, and K. Sakurai, "Influence of width and depth of palatal vault on rigidity of palatal strap: a finite element study," Journal of Prosthodontic Research, vol. 53, no. 2, pp. 95-100, 2009.

[74] M. T. Rodrigues, B. H. Harshitha Gowda, and B. Alva, "Stress distribution in tooth supported removable partial denture fabricated using two different materials: a 3-dimensional finite element analysis," Materials Today: Proceedings, 2021.

[75] H. Sasaki, Y. Takayama, M. Saito, K. Mizuno, M. Goto, and A. Yokoyama, "Effects of splinting on displacement of maxillary canines as abutments of removable partial dentures: a finite element analysis," Prosthodontic Research \& Practice, vol. 6, no. 3, pp. 159-165, 2007.

[76] A. Messias, P. Nicolau, F. Guerra, A. Amaro, L. Roseiro, and M. A. Neto, "Implant-assisted removable partial dentures in mandibular Kennedy class I patients: the impact of implant positioning," in Mediterranean Conference on Medical and Biological Engineering and Computing, Springer, 2019.

[77] O. Ortiz-Puigpelat, A. Lazaro-Abdulkarim, J. M. de MedranoRene, J. Gargallo-Albiol, J. Cabratosa-Termes, and F. Hernandez-Alfaro, "Influence of implant position in implant-assisted removable partial denture: a threedimensional finite element analysis," Journal of Prosthodontics, vol. 28, no. 2, pp. e675-e681, 2019.

[78] T. Ohyama, S. Nakabayashi, H. Yasuda, T. Kase, and S. Namaki, "Mechanical analysis of the effects of implant position and abutment height on implant-assisted removable partial dentures," Journal of Prosthodontic Research, vol. 64, no. 3 , pp. 340-345, 2020.

[79] A. El-Okel and A. O. Elnady, "Influence of location and dimeter of osseointegrated implants associated with distal extension removable partial dentures: (a finite element analysis)," Egypt Dental Journal, vol. 59, pp. 1-10, 2013.

[80] L. D. Cunha, E. P. Pellizzer, F. R. Verri, and J. A. Pereira, "Evaluation of the influence of location of osseointegrated implants associated with mandibular removable partial dentures," Implant Dentistry, vol. 17, no. 3, pp. 278-287, 2008.

[81] A. Fayaz, A. Geramy, Y. Memari, and Z. Rahmani, "Effects of length and inclination of implants on terminal abutment teeth and implants in mandibular CL1 removable partial denture assessed by three-dimensional finite element analysis," Journal of Dentistry, vol. 12, pp. 739-746, 2015.

[82] C. M. de Freitas Santos, E. P. Pellizzer, F. R. Verri, S. L. de Moraes, and R. M. Falcon-Antenucci, "Influence of implant inclination associated with mandibular class I removable partial denture," The Journal of Craniofacial Surgery, vol. 22, no. 2, pp. 663-668, 2011. 